\title{
Figuras para resignificar la práctica profesional de Trabajo Social. Una reflexión con estudiantes de la Universidad de Cartagena en El Caribe colombiano
}

\author{
Alexander Pérez Álvarez ${ }^{1}$
}

Resumen. Este artículo, basado en resultados de una investigación, presenta una cartografía de significados de las prácticas de Trabajo Social, desde la perspectiva de las experiencias e imágenes que han construido sobre la misma los y las estudiantes de último año del Programa de Trabajo Social de la Universidad de Cartagena, Colombia.

Dotar de significados a las prácticas de Trabajo Social requiere un ejercicio investigativo que les reconozca un carácter multisemántico, plural y complejo. En esta medida su invención como objeto de estudio parte de plantear una premisa central, que se refiere a que no podrían ubicarse o clasificarse en una definición o concepción única sino que, por el contrario, son el resultado de construcciones intersubjetivas que requieren un ejercicio teórico y metodológico más centrado en la comprensión que en la explicación; en otras palabras, las prácticas cobran sentido en la interacción y en la percepción de "el aquí y el ahora" que tienen los diferentes sujetos, en este caso los y las estudiantes que las vivencian, y es en esa interacción cargada de múltiples intereses donde las configuran y reconfiguran, otorgándoles elementos de significación que aparentemente pueden ser diversos, opuestos, complementarios o simplemente plurales. Palabras clave: Intervención profesional; prácticas en Trabajo Social; significados; práctica como acción con sentido

\section{[en] Concepts to reinterpret professional social work practice: a reflection with students from Universidad de Cartagena in the Colombian Caribbean region}

\begin{abstract}
Based on the outcomes of a study, this article presents a map of definitions for social work practices from the perspective of the experiences and images that final-year students on the Social Work programme at Universidad de Cartagena, Colombia have constructed in that regard.

Defining social work practices requires an investigative exercise that recognizes their multisemantic, plural and complex nature. This measure involves practices being conceived as an object of study based on a central premise: they could not be located or classified within a single definition or concept, but rather are the result of intersubjective constructions that require a theoretical and methodological exercise focused more on understanding than explanation. In other words, practices gain meaning from interaction and from the perception of the "here and now" held by different subjects - in this case, the students who experience them. It is in this interaction of multiple interests where practices are shaped and reshaped, developing elements of meaning that can be diverse, opposed, complementary or simply plural. Key words: professional intervention; Social Work practices; meanings; practice as meaningful action
\end{abstract}

Sumario: Introducción. 1. Aproximaciones teórico-metodológicas a la práctica en Trabajo Social. 2. Polifonías y Trabajo Social. 3. Trascendiendo lo procedimental. 4. Diálogos desde la perspectiva de la práctica como acción con sentido. 5. Consideraciones finales. 6. Referencias bibliográficas.

Cómo citar: Pérez Álvarez, A. (2018) Figuras para resignificar la práctica profesional de Trabajo Social. Una reflexión con estudiantes de la Universidad de Cartagena en El Caribe colombiano, en Cuad. trab. soc. 31(2), 393-405.

\footnotetext{
Universidad de Cartagena, Colombia

apereza1@unicartagena.edu.co
} 


\section{Introducción}

Es común que en el mundo académico persista una dicotomía donde la práctica se define como una acción instrumental de la teoría, como si el mundo de la acción humana pudiera desprenderse del pensamiento o como si este pudiera limitarse al movimiento categorial de lo simple. Sin embargo, la práctica profesional en Trabajo Social no puede reducirse solo al actuar, sino que es necesario reconocerla como un campo pedagógico de generación, interconexión e integración de conocimientos, y como una acción intencionada que trasciende su carácter histórico de activismo.

Pensar en las prácticas profesionales en Trabajo Social desde la perspectiva de una Universidad pública, como la Universidad de Cartagena, implica comprenderlas como un proceso complejo, dinámico y transversal para la formación, articulado a los propósitos misionales y que se gestiona y desarrolla en interdependencia con las funciones básicas de extensión, docencia e investigación. En este proceso emergen tensiones y múltiples intereses que pueden evidenciarse en un ámbito interno y externo. En cuanto a lo interno, lineamientos de orden político-administrativo y académico a veces tienden a situar las prácticas como un accionar técnico e instrumental, reduciéndolas a un plano operativo; en cuanto al ámbito externo, de orden nacional y global, es clave mencionar que las prácticas se desarrollan en contextos caracterizados por la privatización de la educación y la flexibilización del mundo del trabajo, entre otras.

Podría afirmarse que estas acciones de orden neoliberal naturalizan las desigualdades sociales, llevan a que lo social cada vez esté más cercano al mercado y más alejado de las comunidades $\mathrm{y}$, en muchos de los casos, el afán de ser efectivos tiende a una "desciudadanización” del sujeto (Aquín, 2003). Por ello reivindicar las "prácticas" por la Universidad pública es apelar a su sentido académico, a su apuesta de proyección social e incidencia en la transformación de condiciones de vida.

Con relación a lo metodológico, esta reflexión es producto de un ejercicio de investigación cualitativo con un nivel exploratorio y descriptivo, que tiene como objetivo develar significados que los y las estudiantes ${ }^{2}$ de los últimos semestres de Trabajo Social de la Universidad de Cartagena configuran acerca de la práctica de Trabajo Social. Para desentrañar los significados de las prácticas se acude al interaccionismo simbólico, como el enfoque teórico-metodológico que permite configurar matrices de sentido a los hallazgos construidos por los y las estudiantes participantes del proceso investigativo.

Esto posibilita hablar de la práctica como un objeto de investigación que se significa a partir de la experiencia y también desde los imaginarios producidos sobre la misma. Para ello se empleó como técnicas de recolección de información la entrevista y conversaciones intencionadas con los y las estudiantes de los niveles priorizados, así mismo se realizaron grupos de discusión.

Acercarse a la cotidianidad de los y las estudiantes con una pregunta sobre cómo significan un escenario tan importante para su formación profesional, como es el de las prácticas; es una oportunidad para trascender el rol de asesor o el de profesor; es una posibilidad para reconocerles no solo como sujetos en el contexto curricular, sino también como interlocutores de una experiencia construida por ellos y ellas, con sus voces, temores, imágenes y formas particulares de dotar de significado a dicha experiencia.

Los aportes teóricos y metodológicos del interaccionismo simbólico permiten afirmar que, para dotar de significados a las prácticas, es necesario reconocer en ellas su construcción intersubjetiva ${ }^{3}$. En esta dirección, se podría plantear que es en la interacción donde las prácticas adquieren personalidad simbólica $y$, por lo tanto, múltiples significados que se expresan en relatos, prácticas y creencias.

En esta investigación participaron un total 65 estudiantes: 31 de noveno y 34 de décimo semestre del programa de Trabajo Social. La investigación se centra en estos niveles de formación porque en la propuesta curricular del Programa es, en este último año, cuando el y la estudiante realizan sus prácticas. En noveno semestre se da el momento de inicio, de vinculación formalizada con una Institución; es un momento de expectativas e imaginarios frente a lo que puede ser y debería ser las prácticas. En el semestre décimo, es el momento en que el o la estudiante ya han construido su objeto y están pensando en su trabajo de fin de grado que, para el caso del Programa, está articulado a este proceso; acá se narra sobre lo vivido, se comparte la experiencia y lo aprendido. La subjetividad, puede ser comprendida como la conciencia que se tiene de las cosas desde el punto de vista propio, que se comparte colectivamente en la vida cotidiana. La intersubjetividad sería, por lo tanto, el proceso en el que compartimos nuestros conocimientos con otros en el mundo de la vida (Rizo, 2012). 


\section{Aproximaciones teórico-metodológicas a la práctica en Trabajo Social}

Kisnerman (1998) sitúa la práctica en un lugar determinante y constituyente del Trabajo Social, que rompe con el empirismo y la dota de identidad disciplinar y sentido epistemológico. Desde sus orígenes en el Trabajo Social los debates frente a la práctica han transitado de la construcción empírica a posturas reflexivas y transformadoras; según Martinelli (1992), la institucionalización del Trabajo Social como profesión permitió racionalizar y formalizar las acciones de asistencia, en una alianza entre la burguesía, el estado y la iglesia. En esta lógica, la caridad se constituyó como un dispositivo ordenador que, en su trasfondo, lo que permitía era promover y legitimar la expansión del capital y la naturalización de la pobreza.

Margarita Rozas Pagaza (2000) plantea que, con la transformación de la sociedad tradicional en moderna, la intervención basada en el asistencialismo se reemplazó por la idea de una moral universal construida racionalmente. "Dicha moral universal era coherente con la idea de progreso, felicidad y bienestar que traería dicho proyecto de la modernidad, puesto que el hombre gracias al triunfo de la razón podría construir gradualmente una sociedad perfecta" (p. 15).

Con el paso de los años esta asistencia se iba acompañando de acciones de regulación vinculadas a la higiene y formación en valores, en una perspectiva epidemiológica y conductista, donde los problemas y las "disfunciones" se ubican en los individuos. La práctica del Trabajo Social se coincibe así como una acción de control y vigilancia, como lo plantea Foucault (2002).

Sin embargo, desde mediados de la década del sesenta del siglo XX y en medio del auge de los nuevos movimientos sociales (feministas, sexuales, ambientalistas, campesinos, negros, etc.) es posible identificar un movimiento, conocido como la Reconceptualización del Trabajo Social, y particularmente en América Latina se dio como una apuesta por la construcción de prácticas cercanas a los contextos de desigualdad y exclusión que producía un sistema económico determinado.

En esta vía, el Centro Latinoamericano de Trabajo Social (CELATS, 1976) plantea la práctica del Trabajo Social como una acción que se ejerce en un ámbito de contradicciones y, más allá de mantener el status quo, busca
- por lo menos para el caso latinoamericano y para algunas vertientes no hegemónicas de Europa y Estados Unidos - generar procesos de transformación en la sociedad. De esta manera es posible develar un salto significativo en la profesión que va desde la institucionalización de la caridad, pasando por el control de los individuos y su ajuste a la sociedad, hasta llegar a una acción con interés transformador. Ello permite ver que la práctica en el Trabajo Social no es una acción congelada, sino que se ha transformado en la medida que las sociedades también lo van haciendo. Hacia mediados de la década del setenta, el CELATS definía la práctica del Trabajo Social como un escenario de contradicciones y, en cercanía con el marxismo, presentaba un debate frente a los juegos de intereses y las presiones del ser una labor asalariada.

La práctica del trabajo social aparece descubriendo el carácter contradictorio de las relaciones sociales institucionalizadas y legitimadas por el Estado y las instituciones privadas, dejando de lado las formas caritativas ampliando la labor de estos agentes con el fin de poder enfrentar la realidad social (p.78).

En esta línea es importante señalar algunos asuntos que planteaba este organismo, que siguen aún vigentes y permiten dibujar la práctica del Trabajo Social en tanto universo simbólico; ello es, que existe, en tanto se genera como expresión especializada dentro de un cuadro institucional que presenta las siguientes características: está socialmente determinada en sus rasgos fundamentales; es también producto de sus agentes profesionales; es histórica y cambiante; y exige permanentes redefiniciones frente a los cambios de la cuestión social.

Durante las dos últimas décadas del siglo XX y en este transitar del siglo XXI, los debates y las tensiones han estado vinculados con el establecer una relación intrínseca entre práctica y sistematización; entre acción, transformación y reflexión. La sistematización como un componente vital para recuperar la experiencia, para reflexionar de manera crítica y propositiva, para relacionar teorías y contextos.

Al respecto y como ejemplo, Rosa María Cifuentes propone la sistematización de la práctica del Trabajo Social como "una estrategia para el avance de la reflexión crítica y propositiva sobre la profesión de Trabajo Social" 
(1999, p.11), en este sentido, no es suficiente una acción transformadora si no está soportada en la reflexión de nuestra práctica para aprender de ella y potenciarla. En otras palabras, la práctica emerge como un lugar para construir conocimiento.

Ahora bien, Natalio Kisnerman entiende la práctica como "la instancia verificadora de la teoría y es lo que sistematizada permite modificar y enriquecer la teoría" (1998, p.110). Entonces si se sistematiza la práctica, la teoría ya no sería algo estático e inmutable, sino que podría ser resignificada mientras aporta a la construcción de la práctica.

En esa perspectiva de relacionar teoría con práctica, Karen Healy considera, al contrario que Kisnerman, que la práctica es un espacio más de interrogación que de verificación: "la práctica del trabajo social como base para construir una teoría de la práctica, para interrogar la teoría y viceversa" (2001, p.20). Interrogar a la práctica significa ponerla en cuestión para poder comprender si lo que se ha venido haciendo, e incluso todavía se hace, ha conducido a la realización de acciones intencionadas y a la transformación de desigualdades. Para esta autora, la práctica del Trabajo Social debe poner cuestionar algunos sistemas históricos de dominación como el patriarcado, el racismo, el capitalismo. De esta manera, la practica transita a un espacio crítico y activista, que pone el debate en un accionar emancipador en "un trabajo social antirracista y multicultural, trabajo social anti-opresor y anti-discriminativo, trabajo social feminista, trabajo social marxista" (p.13).

En lo teórico, pueden verse algunas de las múltiples vertientes y maneras de definir la práctica en Trabajo Social como un objeto de reflexión en constante transformación y que se constituye en la relación dialéctica y dialógica de la teoría con la realidad. Por ello, no es posible establecer definiciones únicas o validar unos enfoques particulares por encima de otros. Como se ha visto, la riqueza de la práctica en el Trabajo Social es su configuración polisémica, compleja, a veces contradictoria, y en constante tensión. Ello trae consigo, la necesidad de que la práctica se convierta en un objeto de continua reflexión y problematización, teniendo claro que no es un objeto dado, sino que se construye y potencia en medio de intereses, contextos y momentos particulares.

Nelia Tello considera la intervención profesional del Trabajo Social como un ejercicio fundamentado, transformador y sobre todo, participativo. En ese sentido afirma que es "un ejercicio fundado en el conocimiento, con una intensión y un sentido dado con la interacción con el otro y que si no se tiene en cuenta el sujeto, no se estaría realizando trabajo social (2010, p. 62).

Para continuar tejiendo y llenado de contenido este concepto; Teresa Matus (1999) considera que la intervención está mediada por un sistema de comprensión social constituido por cuatro dimensiones: los cambios contextuales, las diversas perspectivas de teorías sociales, los enfoques epistemológicos y los marcos éticos. Desde esta mirada, es necesario reinterpretar el concepto tradicional técnico-instrumental que se conoce, y situar el debate en un horizonte donde la intervención tenga como fundamento una rigurosa y compleja comprensión social, recapturando la tensión existente entre la teoría y praxis.

El rescate de la intersubjetividad, las singularidades y los diálogos entre teoría y praxis ponen en escena un debate donde los modelos y protocolos preestablecidos esterilizan el quehacer y cosifican al otro en tanto sujeto; la invitación de la autora está en potenciar intervenciones polifónicas que rompan con los determinismos y las lógicas binarias y opresoras.

Rozas Pagaza (2000) define la intervención como una compleja trama de acciones organizadas frente a lo que se ha dado en llamar problemas sociales; es decir, conflictos que generan y expresan algún tipo de ruptura en la vida individual y colectiva en su calidad de miembros de una sociedad históricamente dada.

Desde esta perspectiva, la construcción del objeto de intervención se entiende como un proceso teórico-práctico, en el sentido de que toda intervención tiene una matriz teórica que la sustenta y un instrumental metodológico que le permite recrear dicho concepto en la realidad social. Para la comprensión del objeto es clave constituirlo como campo problemático. En este sentido, el objeto de intervención es una construcción del pensamiento basado en el concepto o los datos que permiten comprender la relación sujeto-necesidad-derechos, llevándolo a la realidad.

En esa vía, también Teresa Matus (2002) propone resignificar el concepto de Trabajo Social, situarlo en un horizonte de intervención que tenga como fundamento una rigurosa y compleja comprensión social, recapturando la tensión existente en el mismo entre teoría 
y praxis. De este modo se busca poner en evidencia que toda intervención es capturada a partir de un lugar teórico, a partir de un modo de ver. Esto significaría que no hay intervención sin interpretación social.

\section{Polifonías y Trabajo Social}

Los y las estudiantes de Trabajo Social han consolidado discursos y maneras de representar y significar su profesión y los componentes que la constituyen. Estas figuras para representar están articuladas a su proceso de formación, a sus experiencias particulares y a sus intereses como sujetos y ciudadanos, en una ciudad y una región caracterizadas por fuertes tensiones de orden social, político y económico; por pertenecer y habitar en una región desigual, heterogénea y pluridiversa.

Una no puede definir el Trabajo Social y la intervención como si eso fuera un asunto solo epistemológico, en lo personal siento que tengo unos referentes que me sirven para orientar unos principios teórico y metodológicos y sé que hay unas apuestas comunes; pero también es cierto, que hablamos de nuestra profesión desde la manera como nos relacionamos con nuestra ciudad, con nuestro entorno. La mayoría de nostras-os vivimos en condiciones de pobreza, en zonas periféricas; para estudiar hemos tenido que resistir y luchar de muchas maneras; en mi caso por ejemplo, por ser mujer, negra, desplazada, en fin (...) esas experiencias me lle- van a mí a pensar en un Trabajo Social feminista, crítico y basado en los derechos y por ende mi práctica ha estado ahí (... ) en tratar de incidir, de transformar (Conversación en asesoría académica con estudiante de décimo semestre, 22 de julio de 2016).

Pensar en un Trabajo Social, cuando uno mismo es parte de las exclusiones que pretende transformar, es el interrogante central en uno de los grupos de discusión y ello convoca a un acto de reflexividad y capacidad de trascender las experiencias de vida al plano académico y profesional.

Con los y las estudiantes identificamos categorías convencionales con las que definimos y demarcamos un lugar referencial y de identidad colectiva: Trabajo Social, intervención y práctica. En esa vía y con esas categorías que, a la vez, son imágenes dotadas de sentido que identifican y relacionan con ideas, conceptos y vertientes (que según ellos y ellas) circulan en textos y en las concepciones de docentes y egresados y egresadas del Programa.

En los grupos de discusión realizados con estudiantes es posible identificar que, frente al Trabajo Social como profesión y disciplina, sitúan reflexiones que vinculan la relación: reflexión -acción- transformación en un quehacer profesional que, además, definen como interdisciplinar y posibilitador de transformaciones sociales; estas concepciones pueden apreciarse de manera diferenciada por semestre de formación en el Cuadro 1.

Cuadro 1. Concepciones de Trabajo Social de estudiantes de Trabajo Social de la Universidad de Cartagena (2016)

\begin{tabular}{|l|l|}
\hline Estudiantes noveno semestre & Estudiantes décimo semestre \\
\hline - $\begin{array}{l}\text { Es un campo social de análisis que permite co- } \\
\text { nocer la realidad social para así transformarla. }\end{array}$ & $\begin{array}{l}\text { Como una profesión de construcción, cambios } \\
\text { y retos en los contextos. }\end{array}$ \\
$\begin{array}{l}\text { Como una disciplina y a la vez como un queha- } \\
\text { cer profesional porque construye y genera co- } \\
\text { nocimientos, pero a la vez reflexiona y acciona } \\
\text { para lograr transformaciones sociales. }\end{array}$ & $\begin{array}{l}\text { Como una profesión transdisciplinar que bus- } \\
\text { ca una intervención sujeto-profesional para la } \\
\text { transformación de una realidad. } \\
\text { Una profesión reflexiva y transformadora }\end{array}$ \\
\hline
\end{tabular}

Fuente: Base de datos construida por el autor, 2016. 
En las definiciones planteadas, el debate por definir Trabajo Social como profesión, disciplina o campo disciplinar es una cuestión que permanece y sobre la cual, no hay acuerdos; lo interesante, en este sentido, es considerar vigente el debate y "dependiendo del cómo se asuma la práctica puede ambas o lo uno o lo otro" (Entrevista Yeiris, estudiante de $10^{\circ}$ semestre).

Se presenta un consenso en los y las estudiantes referido a que el Trabajo Social debe ser reflexivo y su ejercicio transformador y vinculante de los sujetos históricamente excluidos. Esto pone en escena una mirada no solo epistemológica del Trabajo Social, sino también ontológica, donde lo ético, en tanto una pregunta por el "otro", y lo político, frente a buscar agendas públicas de transformación, son clave y constituyentes de la manera como dotan de sentido a la práctica en la profesión.

La intervención en Trabajo Social se reconoce en contextos complejos, como un accionar intencionado que debe estar en capacidad de reconocer la intersubjetividad, potenciar espacios de intercambio, construcción de con- sensos desde el reconocimiento del Otro, en la consolidación de relaciones horizontales que propicien espacios para la construcción de ciudadanía.

En esta experiencia investigativa y en los grupos de discusión se hace visible la apuesta de un Trabajo Social con capacidad de reconocimiento y comprensión de las realidades vividas por los sujetos, interés para recuperar la memoria colectiva de las comunidades, dotar de sentido y significado a los universos simbólicos de los grupos sociales y reivindicar la cotidianidad como una dimensión esencial para conocer y acercarse al otro en sus diferencias (Conclusiones grupo de discusión, noveno semestre, mayo de 2016).

En la siguiente ilustración se presenta un mapa mental construido con estudiantes de último nivel de prácticas y donde se relacionan componentes y dimensiones de la intervención en Trabajo Social. Como puede observarse, prima la relación de horizontalidad entre sujetos y Trabajo Social y una interdependencia entre la fundamentación teórica, la sistematización de la experiencia y el reconocimiento del contexto.

Diagrama 1. Procesos de intervención desde la perspectiva de los y las estudiantes del Programa de Trabajo Social de la Universidad de Cartagena

\section{PROCESOS DE INTERVENCIÓN SOCIAL}

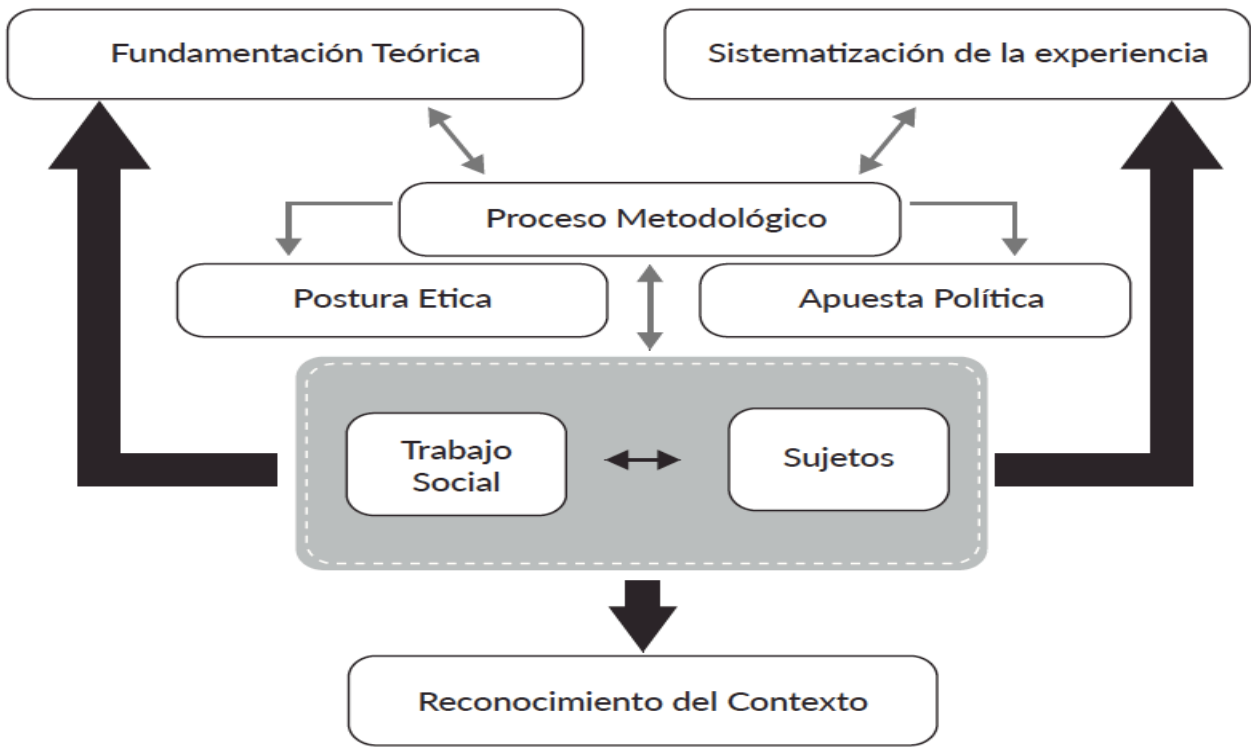

Fuente: Trabajo de campo- Grupo de discusión con estudiantes del décimo semestre (Julio de 2016). 
Puede verse cómo los y las estudiantes consideran que el análisis de contexto es un componente clave de la intervención profesional; seguido de la fundamentación teórica; en tercer lugar, de la sistematización de la experiencia; en cuarto, de la participación de los sujetos y, en quinto lugar, de la definición de la metodología.

Con esta valoración, podría entenderse entonces que la intervención se centra en el análisis del contexto, apoyada en teoría, debe generar reflexión, vincularse de manera participativa y horizontal con los sujetos y con todo ello, poder configurar la estrategia metodológica.
En los grupos de discusión se generaron debates abiertos, lluvias de ideas acerca de estas categorías que constituyen y dotan de especificidad e identidad la intervención profesional. Las categorías que se abordaron en estos espacios investigativos y reflexivos fueron: procesos de intervención y la construcción teórico metodológica de la intervención.

Con relación a los procesos de intervención profesional es importante señalar que el debate permitió poner en escena tensiones, intereses diversos y desacuerdos. Aspecto que enriquece la discusión y permite identificar diversas maneras de significar y llenar de contenido y sentido estas categorías.

Cuadro 2. Formas de resignificar la intervención social y sus aspectos teórico-metodológicos

\begin{tabular}{|c|c|c|}
\hline Categoría & Significados atribuidos & Descripción \\
\hline \multirow{3}{*}{$\begin{array}{l}\text { Intervención } \\
\text { profesional }\end{array}$} & $\begin{array}{l}\text { Acción con sentido reflexi- } \\
\text { va, articuladora y transfor- } \\
\text { madora }\end{array}$ & $\begin{array}{l}\text { Espacio reflexivo intencionado, donde se constru- } \\
\text { ye una relación coherente entre realidad-teoría y } \\
\text { metodologías. } \\
\text { Es una acción intencionada acorde con los inte- } \\
\text { reses de los sujetos con la cual es posible superar } \\
\text { barreras para la garantía de derechos de grupos } \\
\text { sociales excluidos y discriminados dentro de las } \\
\text { lógicas del capitalismo. } \\
\text { Una acción que articula teoría y práctica para } \\
\text { buscar cambios. }\end{array}$ \\
\hline & $\begin{array}{l}\text { Un espacio/acción/campo } \\
\text { problema de retos y desafíos }\end{array}$ & $\begin{array}{l}\text { Espacio para proponer nuevos retos y construir } \\
\text { nuevas metodologías. } \\
\text { Es una acción con la cual es posible encontrar so- } \\
\text { lución a los problemas sociales y donde se pueden } \\
\text { construir nuevos desafíos. } \\
\text { Es un campo problema donde puedo aportar mi } \\
\text { conocimiento y plantear retos para el cambio. }\end{array}$ \\
\hline & Escenario de incertidumbre & $\begin{array}{l}\text { - } \quad \text { El proceso de intervención es un encuentro con lo } \\
\text { inesperado. } \\
\text { - El lugar donde las fórmulas } \\
\text { - } \quad \text { desaparecen y las recetas son insuficientes. } \\
\text { - Donde se encuentra la complejidad del ser huma- } \\
\text { no y se intenta comprender sus maneras de vivir }\end{array}$ \\
\hline
\end{tabular}




\begin{tabular}{|c|c|c|}
\hline Categoría & Significados atribuidos & Descripción \\
\hline \multirow{3}{*}{$\begin{array}{l}\text { Construcción } \\
\text { teorico - } \\
\text { metodológica }\end{array}$} & $\begin{array}{l}\text { Experiencia y conocimiento } \\
\text { de los sujetos como centro } \\
\text { de la relación teoría-meto- } \\
\text { dología }\end{array}$ & $\begin{array}{l}\text { - Se construyen con la participación activa de los } \\
\text { sujetos. } \\
\text { Es fundamental el rescate de la experiencia y } \\
\text { conocimientos de los diferentes actores. Debe ser } \\
\text { horizontal. } \\
\text { La teoría nunca puede estar por encima de los } \\
\text { conocimientos y maneras de representar el mundo } \\
\text { en las comunidades con las que trabajamos. }\end{array}$ \\
\hline & Teoría como ancla & $\begin{array}{l}\text { Impensable un Trabajo Social que no esté susten- } \\
\text { tado en la teoría, en una fundamentación episte- } \\
\text { mológica coherente. } \\
\text { Las prácticas de Trabajo Social deben responder } \\
\text { a una coherencia entre los elementos teóricos que } \\
\text { sustentan y fundamenten y doten de rigurosidad } \\
\text { nuestro accionar. } \\
\text { La postura teórica para no caer en la aridez que } \\
\text { trae la acción meramente instrumentalizada. }\end{array}$ \\
\hline & $\begin{array}{l}\text { Rompimiento de la metodo- } \\
\text { logía como proceso lineal y } \\
\text { técnico. }\end{array}$ & $\begin{array}{l}\text { Las metodologías se construyen en los procesos, } \\
\text { son cambiantes y se articulan a las necesidades y } \\
\text { posibilidades en los campos. } \\
\text { Es clave ir más allá de métodos tradicionales } \\
\text { como grupo, individuo, comunidad. } \\
\text { La metodología también es teoría y es una cons- } \\
\text { trucción compleja y no lineal. }\end{array}$ \\
\hline
\end{tabular}

Fuente: Base de datos de trabajo de campo-Grupos de discusión (2016).

De esta cartografía de significados se encuentran conexiones y flujos comunes que conducen a la construcción de una identidad profesional y a unas manera de ser trabajador y trabajadora social de la Universidad de Cartagena.

Nosotras recibimos una fuerte formación en investigación, eso nos debe permitir consolidar procesos reflexivos y construir conocimiento con y desde los sujetos. Así mismo, por pertenecer a una Universidad Pública, tenemos una postura crítica y de defensa de los derechos. A mí nunca se me olvida, cuando una profe en segundo semestre, nos dijo que es impensable un Trabajo Social que no pueda ser cuestionador y movilizador (Conversación en asesoría de práctica, marzo de 2016).

Reflexionar sobre las maneras como concebimos la intervención es una posibilidad para construir puentes de diálogo entre la teoría-sujetos-realidad, nos permite analizar tensiones a la luz de los contextos y las experiencias particulares y, sobre todo, tener la oportunidad de "consolidar en la región un trabajo social cada vez más humano y movilizador", como plantea una estudiante de décimo semestre en uno de los grupos focales.

\section{Trascendiendo lo procedimental}

Un momento de encuentro entre el saber, el sentir, el compromiso y el rescate del otro, en tanto sujeto, permite empezar a dibujar un mapa de significados alrededor de las prácticas, como un lugar que no pude ser reducido solo a una cuestión procedimental que beneficia y prioriza a unos grupos sociales y unas necesidades por encima de a otros. En un Estado Social de Derecho es la práctica la que consolida una intervención profesional que reconoce los derechos como universales, pero que requiere "considerar las limitaciones de acceso diferencial de los sujetos, tanto al conocimiento, como a los recursos culturales y económicos para garantizar un acceso en igualdad de oportunidades para todos y todas" (Pérez, 2012, p. 276). 
Así mismo, en el trabajo de campo, realizado con los grupos de estudiantes en las prácti- cas académicas, se identificaron tres vertientes de significación sobre esta categoría.

Cuadro 3. Vertientes de significado de las prácticas en Trabajo Social

\begin{tabular}{|l|l|l|}
\hline \multicolumn{1}{|c|}{ Significado atribuido } & \multicolumn{1}{c|}{ Descripción } \\
\hline $\begin{array}{l}\text { Lugar de relacionamien- } \\
\text { to entre teoría- realidad/ } \\
\text { contexto }\end{array}$ & $\begin{array}{l}\text { Es un campo de análisis y de acción donde se ponen en juego todas las } \\
\text { herramientas aprendidas y pone en marcha el saber especializado del } \\
\text { Trabajo Social. }\end{array}$ \\
\hline $\begin{array}{l}\text { Es un proceso donde se relaciona la teoría con la realidad y se desarro- } \\
\text { llan las acciones de intervención. }\end{array}$ \\
$\begin{array}{l}\text { Es el pilar de la profesión y es el campo donde se relaciona teoría y } \\
\text { contexto }\end{array}$ \\
$\begin{array}{l}\text { ye identidad y especifici- } \\
\text { dad de la profesión y se } \\
\text { potencia trasformación } \\
\text { social. }\end{array}$ & $\begin{array}{l}\text { El momento para desarrollar una acción fundamentada en los linea- } \\
\text { mientos propios de la profesión para la trasformación de realidades } \\
\text { sociales. }\end{array}$ \\
\hline $\begin{array}{l}\text { Es una construcción entre sujetos; un agente social y un sujeto que se } \\
\text { subjetiva y que conjuntamente buscan transformar desde la perspec- } \\
\text { tiva de un Trabajo Social critico un campo problemático que afecta el } \\
\text { bienestar. }\end{array}$ \\
$\begin{array}{l}\text { Es un espacio escénico, es decir cambiante, que conlleva la trasforma- } \\
\text { ción social y es lo que permite la especificidad y la construcción de } \\
\text { identidad en la profesión }\end{array}$ \\
\hline $\begin{array}{l}\text { Espacio de confrontación permanente con la realidad de aquello que se } \\
\text { ha aprendido en la academia. } \\
\text { Es ese espacio donde es posible reconocer en conocimiento no solo } \\
\text { está en los libros. }\end{array}$ \\
\hline
\end{tabular}

Fuente: Base de datos de trabajo de campo- Grupos de discusión (2016)

Con esta primera ruta de significados se pasa a analizar lo planteado y, desde ahí, se construye una figura articuladora de esa multiplicidad de voces y sentidos en tanto lo que es, donde se ubica, y lo que permite que, de una u otra manera, sean las categorías que los y las estudiantes buscan llenar de sentido. 


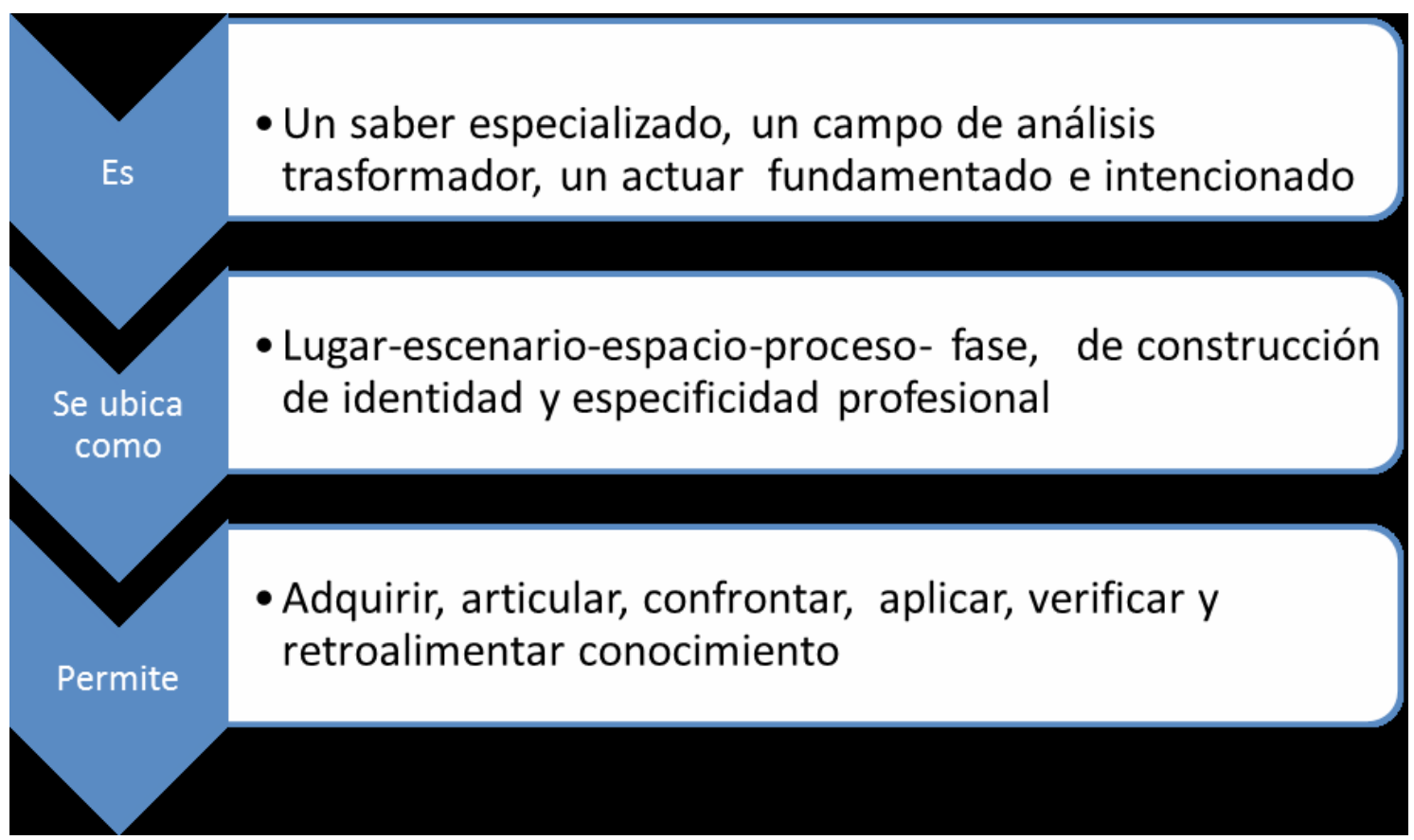

Fuente: Base de datos de trabajo de campo- Grupos de discusión (2016).

4. Diálogos desde la perspectiva de la práctica como acción con sentido

Uno de los hallazgos más significativos de este proceso tiene que ver con el reconocimiento de la práctica en Trabajo Social en tanto acción, y ello está fuertemente articulado con lecturas de autores clave que han orientado su proceso formativo, como es en este caso Max Weber. "Economía y sociedad" de Max Weber (1974) es uno de los textos que referencian significativamente los y las estudiantes al momento de analizar la práctica del Trabajo Social como una acción con sentido. Ha definido de manera sistemática el concepto de "acción social", que puede comprenderse a través de cuatro tipologías: racional con arreglo a fines; racional con arreglo a valores; afectiva y tradicional. Con base en esta clasificación se construyó una cartografía que permite reflexionar y relacionar contextos de práctica con textos teóricos abordados en la formación.

En el cuadro 4, se presenta una relación entre los tipos de acción propuestos por Max Weber, su respectiva descripción y una ejemplificación de cómo ese tipo de acción se operacionaliza y vivencia en algunas prácticas de Trabajo Social que se analizaron en los grupos de discusión y en la experiencia de asesoría académica con los y las practicantes. 
Cuadro 4. Ejemplos de práctica identificadas con los y las estudiantes, según los tipos de acción en Max Weber

\begin{tabular}{|c|c|c|}
\hline Tipos de acción & Descripción & Ejemplos identificados \\
\hline $\begin{array}{l}\text { Racional con } \\
\text { arreglo a fines }\end{array}$ & $\begin{array}{l}\text { Determinada por expecta- } \\
\text { tivas en el comportamiento } \\
\text { tanto de objetos del mundo } \\
\text { exterior como de otros } \\
\text { hombres y utilizando estas } \\
\text { expectativas como "con- } \\
\text { diciones" o "medios" para } \\
\text { el logro de fines propios } \\
\text { racionalmente sopesados y } \\
\text { perseguidos }\end{array}$ & $\begin{array}{l}\text { Las prácticas orientadas al cumplimiento de accio- } \\
\text { nes de bienestar bajo lógicas del modelo neolibe- } \\
\text { ral y con una idea externa de progreso. En ellas, } \\
\text { predomina la racionalidad formal. El desarrollo de } \\
\text { determinados ejercicios y estrategias metodológicas } \\
\text { para garantizar el adiestramiento de los sujetos y las } \\
\text { comunidades. } \\
\text { Generalmente priman solo los intereses de la Insti- } \\
\text { tución donde él o la estudiante realiza su práctica. }\end{array}$ \\
\hline $\begin{array}{l}\text { Racional con } \\
\text { arreglo a valores }\end{array}$ & $\begin{array}{l}\text { Determinada por la creencia } \\
\text { consciente en el valor - éti- } \\
\text { co, estético, religioso o de } \\
\text { cualquier otra forma como } \\
\text { se le interprete - propio y } \\
\text { absoluto de una determina- } \\
\text { da conducta, sin relación } \\
\text { alguna con el resultado, o } \\
\text { sea puramente en mérito a } \\
\text { ese valor. }\end{array}$ & $\begin{array}{l}\text { Está motivada en el "valor" que se le confiere a la } \\
\text { acción. Se parte del compromiso de la Universidad } \\
\text { o de la profesión con la Ciudad y Región. Tiene } \\
\text { una orientación ética y política hacía programas de } \\
\text { ayuda humanitaria y extensión solidaria. En este } \\
\text { sentido puede mirarse la propuesta de "acompaña- } \\
\text { miento" a comunidades en el marco valorativo del } \\
\text { respeto a sus planteamientos e iniciativas }\end{array}$ \\
\hline Afectiva & $\begin{array}{l}\text { Especialmente emotiva, } \\
\text { determinada por afectos y } \\
\text { estados sentimentales ac- } \\
\text { tuales. }\end{array}$ & $\begin{array}{l}\text { Se rige por aspectos emotivos y afectivos: "los } \\
\text { niños pobres y/o abandonados", "los campesinos } \\
\text { expropiados".... La motivación afectiva de la prác- } \\
\text { tica está basada en el sentimiento, un componente } \\
\text { importante de revisar en un contexto de la idiosin- } \\
\text { crasia judeo- cristiana que nos caracteriza. }\end{array}$ \\
\hline Tradicional & $\begin{array}{l}\text { Determinada por una cos- } \\
\text { tumbre arraigada }\end{array}$ & $\begin{array}{l}\text { Ha sido costumbre la realización de prácticas en esa } \\
\text { institución que han relacionado a la Universidad } \\
\text { con determinados barrios, centros y organizaciones, } \\
\text { a pesar de su carga instrumental y asistencialista se } \\
\text { mantienen en los imaginarios por tradición. }\end{array}$ \\
\hline
\end{tabular}

Fuente: Elaborado con base en los planteamientos teóricos de M. Weber (1974) y las discusiones en los grupos de discusión (2016).

Con relación a la anterior clasificación es importante aclarar que, para este autor, la acción no es acción meramente individual: es acción social. Es decir, toda acción está orientada por la acción de otros en lo que se ha denominado la "relación social", en el sentido de la reciprocidad ofrecida y esperada por los actores. Otra precisión metodológica es que esta clasificación corresponde a "tipos ideales"; pero la cotidianidad encontramos que se expresan de manera vinculante y mezclada, en una trama de significados y símbolos, como ya se ha mencionado en el apartado anterior. Sin embargo, desde la perspectiva weberiana, está claro que cada acción está determinada fundamentalmente por un tipo de orientación.

En esta perspectiva, las clasificaciones sobre la acción social, donde los sentidos y los intereses ponen en escena fines, medios y resultados, son una posibilidad de búsqueda de significados que nos lleva a pensar, en una primera medida, que las prácticas -en términos habermasianos- se deben comprender como una acción estratégica y deliberativa y - en términos weberianos- como una acción con sentido que debe estar mediada por la reflexión del interés que la antecede. En esta misma vía, Bourdieu considera ineludible la relación 
pensamiento y acción, por ello, cree necesario abandonar la concepción determinista objetivista que ordena el mundo en lógicas binarias, reduciendo el conocimiento a una realidad que antecede al sujeto, a una relación práctica con el mundo, donde este es quien le impone su presencia, sus urgencias, las cosas por hacer o decir, "sus cosas hechas para ser dichas", que domina directamente los gestos o las palabras sin desarrollarse nunca como un espectáculo.

Para la práctica, los estímulos no existen en su verdad objetiva de detonantes condicionales y convencionales, solo actúan a condición de reencontrar a los agentes ya condicionados para reconocerlos. El mundo práctico que se constituye en la relación con el habitus, como sistema de estructuras cognitivas y motivacionales, es un mundo de fines ya realizados, modos de empleo o caminos a seguir, y de objetos dotados de un "carácter teleológico permanente (1991, p. 94).

Es decir, que el elemento de los fines es insoslayable y que las estructuras profundas de significación -los habitus- están inscritos en el cuerpo de los actores y en sus pensamientos.

\section{Consideraciones finales}

Podríamos afirmar que hablar de significados, que los y las estudiantes de últimos semestres construyen acerca de las prácticas en Trabajo Social, nos lleva a visualizarlas como un sistema complejo de interpretación simbólica, al que acuden los diferentes actores protagonistas de la misma para describirlas e interpretarlas, según sus referentes epistemológicos y su realidad circundante, su mundo de vida. Reconociendo que, en muchas de estos significados, emergen sistemas enraizados en la cultura y en el lenguaje y sus relaciones van más allá de los términos sintácticos o exclusivamente normativos.

Como punto de encuentro en la diversidad de concepciones, es posible identificar dos figuras permanentes en el discurso: una primera, referida al cómo se vivencian y otra, que hace alusión al cómo las imaginan. Dos figuras que más que contradictorias, son complementarias, pues la primera las ubica en un discurso práctico, situándolas y concibiéndolas en lo que sienten los actores que son o que han sido y, por otro lado; en un discurso imaginado, soñado e idealizado que las define en lo que deberían ser, es decir, en una perspectiva de futuro.

Con relación a lo académico, se observa una formación integral intencionada desde la perspectiva de las dimensiones socio-humanistico-científicas. En esta última dimensión, el Programa cobra relevancia al hacer reflexiones en torno a la disciplina y a la relación teoría práctica. Lo que se plantea en varias de estas experiencias es una relación de sujeción, puesto que la teoría es una condición para el desarrollo de la práctica.

En esta misma vía, la sistematización aparece como una actividad inherente al desarrollo de la experiencia y cabe resaltar que acá su concepción y rigurosidad se corresponden con una concepción de la sistematización como modalidad de investigación.

Así mismo, en las prácticas reconocidas se encuentra una alusión al trabajo por proyectos algunos de los cuales utilizan herramientas propias de los modelos investigativos de tipo cuantitativo y cualitativo, con estrategias e instrumentos como: diarios de campo, entrevistas, registros, visitas domiciliarias y observación de campo. Esto no significa que existe una articulación con la investigación y, por lo tanto, una intención en generar conocimiento, pero sí es una apuesta en el plano de lo imaginado y de lo esperado por los y las estudiantes.

En estas experiencias, el impacto académico se refleja en la vinculación de un número significativo de docentes y estudiantes, y en la posibilidad de interactuar con distintos escenarios, actores y contextos que posibilitan configurar estrategias diversas que enriquecen la formación de los estudiantes. No se puede desconocer que la práctica demanda ajustes y una acomodación permanente de la experiencia in situ de acuerdo a la complejidad del contexto.

Se encuentra que, en la mayoría de las prácticas reconocidas, la evaluación y el seguimiento se hacen de manera puntual, lo que trae como consecuencia que los resultados no se trasfieran a la modificación de las propuestas. En aquellas prácticas que conciben este proceso de manera intencionada y permanente, se logran revertir los resultados de la evaluación como aprendizajes que nutren los procesos curriculares y por ende las prácticas académicas. 


\section{Referencias bibliográficas}

Aquin, Nora (2003). El Trabajo Social y la identidad profesional. En: Nuevos escenarios y práctica profesional: una mirada crítica desde el Trabajo Social. Buenos Aires: Editorial Espacio.

Bourdieu, Pierre (1991). El sentido práctico. Madrid: Taurus.

CELATS. (1976). Delimitación del espacio profesional del Trabajo Social. Documento virtual. Recuperado de: http://www.ts.ucr.ac.cr/binarios/pela/pl-000340.pdf. (Consultado el 12/11/2016)

Cifuentes, Rosa María (1999). La sistematización de la práctica del Trabajo Social. Buenos Aires: Lumen/ HVhumanitas.

Foucault, Michel (2002).Vigilar y castigar. México: Siglo XXI.

Healy, Karen (2001). Trabajo Social: perspectivas contemporáneas. Madrid: Ediciones Morata.

Kisnerman, Natalio (1998). Pensar el Trabajo Social. Buenos Aires: Lumen/Hvmanitas.

Matus, Teresa (2002). Propuestas contemporáneas en Trabajo Social: Hacia una intervención polifónica. Buenos Aires: Espacio Editorial.

Matus, Teresa (1999). Apuntes sobre la intervención social. Recuperado de: https://trabajosocialucen.files. wordpress.com/2012/04/apuntessobreintervencionsocial.pdf(Consultado el 2/08/2016).

Pérez, Alexander (2012). De la diferencia como amenaza a la diversidad como potencia. Reflexiones en torno a la relación entre ciudadanía intercultural e intervención en lo social. Revista Eleuthera, 7. Manizales: Universidad de Caldas.

Rizo, Marta (2012). Imaginarios sobre la comunicación. Algunas certezas y muchas incertidumbres en torno a los estudios de comunicación hoy. Barcelona: Universidad de Barcelona.

Rozas Pagaza, Margarita (2006). La profesionalización en Trabajo Social: Rupturas y continuidades, de la reconceptualización a la construcción de proyectos ético-políticos. Buenos Aires: Espacio Editorial.

Tello Peón, Nelia (2010). Ires y venires de la intervención de Trabajo Social. Trabajo Social,1. México: UNAM.

Shuttz, Alfred. (1993). La comprensión significativa del mundo social. Introducción a la sociología comprensiva. Barcelona: Paidós.

Weber, Max. (1974). Economía y Sociedad. México: Fondo de Cultura Económica. 